\title{
Handelspolitik gegen politische Freiheit
}

\author{
Birgit Mahnkopf
}

$D$ er Welthandel, seit drei Dekaden wichtigster Motor der Globalisierung, ist in den letzten Jahren ins Stottern geraten. Das lässt die Alarmglocken der Freihändler läuten. Denn eine vergleichbare Entwicklung hatte es bislang nur in den Jahren der „De-Globalisierung", zwischen 1912 und 1950, gegeben. Und auch die Dampfwalze der Liberalisierung hat auf der multilateralen Ebene der World Trade Organization (WTO) seit Jahren an Fahrt verloren, nicht zuletzt aufgrund des ausgeprägten Widerstands gegen eine weitere Liberalisierung des globalen Wirtschaftsgeschehens vonseiten einflussreicher Schwellenländer.

Vor diesem Hintergrund überrascht es wenig, dass neue regionale und bilaterale Handels- und Investitionsabkommen angestrebt bzw. derzeit zwischen der EU und (Gruppen von) anderen Staaten verhandelt werden. Um traditionelle Handelsfragen geht es hier allerdings nicht. Ob es sich um die Transatlantische Handels- und Investitionspartnerschaft zwischen der EU und den USA (TTIP), das kurz vor dem Abschluss stehende Wirtschafts- und Handelsabkommen zwischen der EU und Kanada (CETA) oder um das Abkommen zum Handels- mit Dienstleistungen (TISA) dreht, welches zeitgleich zwischen der EU und den Regierungen von 23 Ländern verhandelt wird, auf die mehr als zwei Drittel des globalen Handels mit Dienstleistungen entfallen: alle diese Abkommen haben vor allem das Ziel, die Freiheit von Regierungen, zu regieren, einzuschränken - und dies weit über die Amtszeit der gegenwärtigen Regierungsvertreter hinaus.

Selbstverständlich spielen bei all diesen Abkommen längerfristige geopolitische Überlegungen eine wichtige Rolle. Geht es für die „alten“ Wirtschaftsmächte aufbeiden Seiten des Atlantiks doch darum, den wachsenden Einfluss insbesondere der BRICS-Staaten (Brasilien, Russland, Indien, China, Südafrika) einzudämmen. Daher sind sowohl die USA als auch die EU bestrebt, technische und regulatorische Standards festzuschreiben, die den Interessen ,ihrer" transnationalen Unternehmen zugutekommen, bevor die neuen Wirtschaftsmächte stark genug sind, ihrerseits die "Regeln des globalen Spiels" in und außerhalb der WTO zu definieren. Im Kern aber handelt es sich beim TTIP und vor allem bei TISA darum, politische Regulierungen auszuhebeln, die heute oder in der näheren Zukunft die Gewinne von transnationalen Unternehmen und deren Anteilseignern respektive die Renditen von institutionellen oder privaten Geldgebern schmälern könnten. Deshalb sollen viele politische Regulierungen im Namen von „regulatorischer Kohärenz"zwischen den vertragsschließenden Staaten angeglichen werden.

Dabei muss mit einem Absenken der "höheren“ EU-Standards auf das "niedrigere" US-Niveau gerechnet werden, etwa beim Schutz von Umwelt, abhängig Beschäftigten und Verbrauchern. Konzerne der europäischen Biotechnologie, denen die eingeschränkte Nutzung von genmodifizierten Verfahren in der EU ein Dorn im Auge ist, oder Unternehmen der europäischen chemischen Industrie, die Auflagen der europäischen REACH-Richt- linie umgehen wollen, drängen schon heute darauf, global unter denselben Wettbewerbsbedingungen operieren zu können wie ihre US-amerikanischen Konkurrenten. Nur diejenigen Regeln sollen gelten, die für Unternehmen „am wenigsten belastend“ sind. Als Belastung für gewinnorientierte Unternehmen gelten prinzipiell alle politischen Entscheidungen, die aus ihrer Sicht „kostentreibend“ sind, also dazu führen könnten, dass die Gewinne zu einem Zeitpunkt X geringer ausfallen als zum Zeitpunkt der Investitionsentscheidung angenommen wurde. Nahezu alle rechtlichen Regeln fallen darunter, die in staatlicher Verantwortung erlassen werden, sei es bei der Liberalisierung und Lizenzvergabe in der Wasser-und Abfallentsorgung, für den Betrieb von Kraftwerken, Gesundheits- oder Bildungseinrichtungen, sei es, dass staatliches Handeln den digitalen Handel betrifft, dass eine auch nur partielle Re-Regulierung von Finanzmärkten beabsichtigt wäre oder gar eine Kehrtwende in der Energiepolitik. Denn in all diesen Fällen könnten sich bereits getätigte Investitionen als ,sunk assets“erweisen: in den Sand gesetzte Investitionen, die keine, auf jeden Fall nicht die erwartete Rendite abwerfen. Die Bürger sollen für die Rendite zahlen.

Besonders umstritten ist das in allen neuen Vertragsentwürfen enthaltene Prinzip der Klagemöglichkeiten von Unternehmen gegen Entscheidungen von Staaten, die von Ersteren als eine Art „indirekte Enteignung" betrachtet werden können. Dieses Prinzip ist schon seit Langem in den Verträgen zur Nordatlantischen Freihandelszone (NAFTA) verankert. Gleiches gilt für eine wachsende Zahl von bilateralen Investitionsschutzabkommen zwischen der EU und Entwicklungsländern. Fragt sich nur, wieso Unternehmen mit Sitz in den USA oder in der EU zukünftig eine deutlich höhere Investitionssicherheit brauchen. Sind nicht beispielsweise die rechtlichen Rahmenbedingungen für Investitionen in Deutschland ein wesentlicher Grund dafür, weshalb ausländische Investoren schon heute mehr als die Hälfte der Aktien an den 30 Unternehmen des Deutschen Aktienindex halten?

Es geht wohl eher darum, durch die Androhung von millionenschweren Entschädigungszahlungen Regierungen langfristig daran zu hindern, von ihrer demokratischen Freiheit Gebrauch zu machen - um beispielsweise bestimmte Sektoren der Wirtschaft unter öffentliche Kontrolle zu stellen oder um bereits eingeleitete Privatisierungsmaßnahmen wieder rückgängig zu machen. TTIP und Co. sollen dafür sorgen, dass jede „sozial-ökologische Wende“ auch in Zukunft ausgeschlossen bleibt.

Birgit Mahnkopf, Prof. Dr., lehrt Europäische Gesellschaftspolitik an der Hochschule für Wirtschaft und Recht (HWR) Berlin.

mahnkopf@hwr-berlin.de 